\title{
ANALYSIS OF FACTORS AFFECTING THE APPLICATION OF AUSTRALASIAN TRIAGE SCALE (ATS) IN EMERGENCY DEPARTEMENT NGUDI WALUYO WLINGI HOSPITAL
}

\author{
Mohammad Nur Firdaus', Setyowati Soeharto², Dewi Kartikawati Ningsih ${ }^{3}$ \\ ${ }^{1}$ Master of Nursing Program Faculty of Medicine Universitas Brawijaya \\ ${ }^{2,3}$ Department of Nursing, Medical Faculty, Universitas Brawijaya
}

\begin{abstract}
Indonesia doesn't have a national standard for triage system which means implementation in each hospital can be different. Nurses have an important role in the application of triage. The Australasian Triage Scale method (ATS) is one of the triage system in the world used in some countries including Indonesia but it is very difficult to implementation in overcrowded emergency departement. Nurses ratio and unstandard triage room make the ATS standart times is difficult to achieve. The aim of this study was to analyze the various factors affecting Australasian Triage Scale (ATS) in emergency departement Ngudi Waluyo Wlingi Hospital. We used quantitative research with cross sectional approach and the respondent are 28 nurses in Emergency Departement Ngudi Waluyo Wlingi Hospital. Univariate analysis is used to know the description of each variable. Fisher test to determine the relationship between variables. Logistic regression analysis to determine the most dominant factor affecting the application of Australasian Triage Scale. Fisher test result show p-Value as follows: performance factor (leadership), $p=$ $0.028<\alpha=0,05$, client factor (waiting time) $p=0.011<\alpha=0,05$, equipment factor (triage documentation) $p=0,036<\alpha=0,05$, staff requirements factor (education) ) $p=0.013<\alpha=0,05$, staff requirements factor (training) $p=0.036<\alpha=0,05$ The result of logistic regression shows staff requirements factor (education) $p=0.019<\alpha=0.05$ with OR 0.059. In conclusion there is a significant affecting between performance leadership factor, waiting time factor, triage documentation factor,education factor, training factor on the application of ATS and education is a dominant factor to predict the accuracy of the application of ATS.
\end{abstract}

Keywords: leadership factor, waiting time factor, triage documentation factor,education factor, training factor, application of ATS

\begin{abstract}
ABSTRAK
Indonesia belum mempunyai standar nasional penerapan sistem triase sehinnga dalam pelaksanaannya pada setiap rumah sakit bisa berbeda. Perawat mempunyai peranan penting dalam penerapan triase Metode Australasian Triage Scale (ATS) merupakan salah satu dari beberapa sistim triase di dunia yang banyak di gunakan di beberapa Negara termasuk Indonesia tetapi sangat sulit diterapkan karena overcrowded instalasi gawat darurat yang relatif tinggi, rasio perawat yang tidak ideal serta ruang triase yang tidak berstandar sehingga target pencapaian waktu yang ditetapkan sistem ATS sulit dicapai. Tujuan penelitian ini adalah menganalisis berbagai faktor yang mempengaruhi Australasian Triage Scale (ATS) Di IGD RSUD Ngudi Waluyo Wlingi Kabupaten Blitar. Metode penelitian ini adalah kuantitatif dengan pendekatan cross sectional dan sebagai responden adalah perawat IGD RSUD Ngudi Waluyo Wlingi Kabupaten Blitar sebanyak 28 orang Analisis univariat digunakan untuk mengetahui gambaran masing-masing variabel. Uji Fisher untuk mengetahui hubungan antar variabel dan analisis regresi logistik untuk mengetahui faktor yang paling mempengaruhi penerapan ATS. Hasil uji Fisher menunjukan $p$-Value sebagai berikut faktor kepemimpinan, $p=0.028<\alpha=0,05$, faktor waiting time $p=0.011<\alpha=0,05$, faktor dokumentasi triase $p=0.036<\alpha=0,05$, faktor pendidikan $p=0.013<\alpha=0,05$, faktor pelatihan $p=0.036<\alpha=0,05$. Hasil regresi linier menunjukkan faktor pendidikan $p=0.019<\alpha=0,05$ dengan OR 0.059. Hasil penelitian ini terdapat pengaruh yang bermakna antara faktor kepemimpinan, waiting time, dokumentasi triase, pendidikan dan pelatihan terhadap penerapan ATS dan merupakan faktor prediktor paling berpengaruh adalah pendidikan yang dapat digunakan untuk memprediksi keakuratan penerapan ATS.
\end{abstract}

Kata Kunci: kepemimpinan, waiting time, fdokumentasi triase, pendidikan dan pelatihan, penerapan ATS

Jurnal Ilmu Keperawatan, Vol. 6: No.1 Mei 2018; Korespondensi : Muhammad Nur Firdaus. Universitas Brawijaya. Jalan Veteran, Ketawanggede, Lowokwaru, Ketawanggede, Kec. Lowokwaru, Kota Malang, Jawa Timur 65145. Email : firdausmnurs2014@gmail.com 


\section{PENDAHULUAN}

Pada saat jumlah klien melebihi jumlah petugas, maka diperlukan sistem triase. Triase merupakan suatu sistem yang berfungsi untuk menyeleksi klien berdasarkan tingkat kegawatdaruratan untuk memberikan prioritas pelayanan kepada klien. Tujuan triase adalah agar klien mendapatkan pelayanan yang optimal serta menurunkan angka morbiditas dan mortalitas, mengidentifikasi klien yang membutuhkan tindakan resusitasi segera, menetapkan klien ke area perawatan untuk memprioritaskan dalam perawatan dan untuk memulai tindakan diagnostik atau terapi. (UndangUndang Republik Indonesia nomor 44 tentang rumah sakit, 2009; Fitzgerald, 2010). Triase dapat ditentukan dengan kebutuhan terbesar klien/korban untuk segera menerima perawatan secepat mungkin.

Penerapan triage yang kurang dan belum memadai akan membahayakan kehidupan klien yang tiba di IGD. Tindakan pengobatan kepada klien dalam urutan kedatangan tanpa penilaian sebelum menentukan tingkat kegawatan dari penyakitnya atau tanpa melakukan triage terlebih dahulu dapat mengakibatkan penundaan intervensi klien dengan kondisi kritis sehingga berpotensi mematikan ( Baker 2009, Nolane et al 2011, Aloyce et al 2014).

Indonesia belum mempunyai standart nasional tentang system triage sehingga dalam pelaksanaan penerapan triage setiap rumah sakit bisa berbeda beda. Metode Australasian Triage Scale (ATS) merupakan salah satu dari beberapa sistim triage di dunia yang banyak di gunakan di beberapa Negara termasuk Indonesia.
Metode Australian Triage Scale (ATS) dalam menentukan prioritas hanya memberikan gambaran secara singkat mengenai lamanya waktu klien menerima tindakan dan diterapkan di negara negara maju dengan fasilitas yang baik (Gerdtz, 2009). Hal ini sangat sulit diterapkan di Indonesia karena overcrowded instalasi gawat darurat yang relatif tinggi, rasio perawat yang tidak ideal serta ruang triage yang tidak tidak berstandar akan membuat waiting time semakin lama sehingga target pencapaian waktu yang ditetapkan sistem ATS akan sulit dicapai(Lee, et al, 2011).

Penelitian yang dilakukan oleh Saktiwirotomo dan Emaliyawati 2016 di IGD RSI PKU Muhamadiyah Pekajangan Pekalongan membuktikan bahwa penggunaan metode Australasian Triage Scale lebih efektif dibandingkan triase tiga tingkat dalam penerapan di IGD. Penelitian di RS Puri Indah Jakarta menemukan bahwa pengetahuan, keterampilan dan sikap perawat mempunyai pengaruh terhadap penerapan triage bila faktor-faktor tersebut tidak dilaksanakan secara optimal dapat menyebabkan kesalahan dalam pengambilan keputusan dan menyebabkan kecacatan pada klien (Australian Triage Process Review 2011 , Anderson et al 2007, Lusiana 2011, Jansen et al 2011 dan Safari 2012). Emergency Nursing Association (2014) menyatakan bahwa keterampilan dan latar belakang pendidikan yang dimiliki perawat akan mempengaruhi penerapan ATS.

IGD RSUD Ngudi Waluyo Wlingi menerapkan sistem triage Australian Triage Scale (ATS) pada awal 2016. Hasil observasi di IGD RSUD Ngudi Waluyo Wlingi 
didapatkan bahwa penerapan ATS (Australasian Triage Scale) masih belum terlihat. Berdasarkan latarbelakang tersebut peneliti ingin mengetahui faktor faktor yang mempengaruhi penerapan Australasian Triage Scale (ATS) Di IGD RSUD Ngudi Waluyo Wlingi Kabupaten Blitar.

\section{METODE}

Penelitian ini merupakan jenis penelitian kuantitatif dengan pendekatan cross sectional, yang bertujuan untuk menganalisis pengaruh antara variabel independen (faktor kinerja, faktor klien, faktor ketenagaan, faktor perlengkapan) dan variabel dependen (penerapan ATS). Pengambilan data dilakukan sebanyak satu kali, pada bulan Juni sampai dengan Juli 2017. Untuk mengetahui gambaran dari setiap variabel yang diteliti digunakan analisis univariat. Untuk mengetahui hubungan antar variabel digunakan uji Fisher dan untuk mengetahui faktor yang paling dominan dalam mempengaruhi penerapan ATS digunakan uji regresi logistik.

\section{HASIL PENELITIAN}

\section{Data umum dan distribusi frekuensi} Responden

Berdasarkan penelitian yang telah dilakukan diperoleh hasil sebagai berikut:

\section{Tabel 1. Data umum Responden}

\begin{tabular}{|c|c|c|c|c|}
\hline NO & \multicolumn{2}{|c|}{ KARAKTERISTIK } & JUMLAH & $\%$ \\
\hline \multirow[t]{2}{*}{1} & \multirow[t]{2}{*}{ Jenis Kelamin } & laki-laki & 15 & 53,6 \\
\hline & & Perempuan & 13 & 46,4 \\
\hline \multirow[t]{2}{*}{2} & \multirow[t]{2}{*}{ Umur } & $20-40$ & 20 & 71,4 \\
\hline & & $>40$ & 8 & 28,6 \\
\hline \multirow[t]{2}{*}{3} & \multirow[t]{2}{*}{ Pendidikan } & $\begin{array}{l}\text { Tingkat } \\
\text { pendidikan D3 }\end{array}$ & 22 & 78,6 \\
\hline & & $\begin{array}{l}\text { Tingkat } \\
\text { pendidikan } \\
\text { diatas D3 } \\
(\mathrm{S} 1, \mathrm{~S} 2)\end{array}$ & 6 & 21,4 \\
\hline \multirow[t]{3}{*}{4} & \multirow[t]{3}{*}{ Lama Bekerja } & $0-2$ & 19 & 67,8 \\
\hline & & $3-5$ & 6 & 21,5 \\
\hline & & $>5$ & 3 & 10,7 \\
\hline \multirow[t]{3}{*}{5} & \multirow{3}{*}{$\begin{array}{l}\text { Status Kepegawa } \\
\text { lan }\end{array}$} & PNS & 16 & 57,1 \\
\hline & & Honorer & 12 & 42,8 \\
\hline & & Magang & - & - \\
\hline \multirow[t]{2}{*}{6} & \multirow[t]{2}{*}{ Pelatihan } & $\begin{array}{l}\text { Belum } \\
\text { tersertifikasi }\end{array}$ & 7 & 25 \\
\hline & & $\begin{array}{l}\text { Tersertifikasi(BT } \\
\text { LS/ACLS/ATLS/ } \\
\text { GELS/PPG) }\end{array}$ & 21 & 75 \\
\hline
\end{tabular}

Sumber: Data Primer (2017) 
Tabel 2. Hasil Analisis univariat

\begin{tabular}{|c|c|c|c|c|}
\hline \multicolumn{2}{|c|}{ Variabel } & \multirow{2}{*}{$\begin{array}{c}\begin{array}{c}\text { Frekuensi } \\
\text { (f) }\end{array} \\
19\end{array}$} & \multirow{2}{*}{$\begin{array}{c}\begin{array}{c}\text { Prosentase } \\
(\%)\end{array} \\
67.9\end{array}$} & \multirow{2}{*}{$\begin{array}{c}\text { OR (IK } \\
95 \%) \\
51.1-85.2\end{array}$} \\
\hline Kinerja & Baik & & & \\
\hline & Kurang Baik & 9 & 32.1 & $28.8-35.3$ \\
\hline \multirow[t]{2}{*}{$\begin{array}{l}\text { Klien (waiting } \\
\text { time) }\end{array}$} & $\begin{array}{l}\text { Sesuai } \\
\text { standar }\end{array}$ & 20 & 71.4 & $69.9-72.8$ \\
\hline & $\begin{array}{l}\text { Tidak Sesuai } \\
\text { standar }\end{array}$ & 8 & 28.6 & $27.2-45.3$ \\
\hline \multirow{2}{*}{$\begin{array}{l}\text { Perlengkapan } \\
\text { (dokumentasi } \\
\text { triase) }\end{array}$} & Diisi lengkap & 21 & 75 & $58.9-91.0$ \\
\hline & $\begin{array}{l}\text { Diisi kurang } \\
\text { lengkap }\end{array}$ & 7 & 25 & $8.9-41.0$ \\
\hline \multirow[t]{2}{*}{$\begin{array}{l}\text { Ketenagaan } \\
\text { (pendidikan) }\end{array}$} & $\begin{array}{l}\text { Tingkat } \\
\text { pendidikan } \\
\text { diatas D3 }\end{array}$ & 6 & 21.4 & $8.9-36.6$ \\
\hline & $\begin{array}{l}\text { Tingkat } \\
\text { pendidikan } \\
\text { D3 }\end{array}$ & 22 & 78.6 & $63.4-93.8$ \\
\hline \multirow{2}{*}{$\begin{array}{l}\text { Ketenagaan } \\
\text { (pelatihan) }\end{array}$} & Tersertifikasi & 21 & 75 & $58.9-91.0$ \\
\hline & $\begin{array}{l}\text { Belum } \\
\text { Tersertifikasi }\end{array}$ & 7 & 25 & $8.9-41.0$ \\
\hline \multirow[t]{2}{*}{ Penerapan ATS } & Akurat & 18 & 64.3 & $46.5-82.0$ \\
\hline & Tidak Akurat & 10 & 35.7 & $17.9-53.4$ \\
\hline
\end{tabular}

Sumber: Data Primer (2017)

\section{Faktor yang mempengaruhi penerapan ATS}

\section{Tabel 1. Hasil Analisis bivariat}

\begin{tabular}{lccc}
\hline \multicolumn{1}{c}{$\begin{array}{c}\text { Variabel } \\
\text { Independent }\end{array}$} & $\begin{array}{c}\text { Variabel } \\
\text { Dependent }\end{array}$ & $\begin{array}{c}\text { OR } \\
\text { Cl 95\% }\end{array}$ & $\begin{array}{c}\mathrm{p} \\
\text { Value }\end{array}$ \\
\hline $\begin{array}{l}\text { Faktor kinerja } \\
\text { (kepemimpinan) }\end{array}$ & Penerapan ATS & $7,5(1,26-44.085)$ & 0,028 \\
Faktor klien & & & \\
(waiting time) & Penerapan ATS & $12(1.725-$ & 0,011 \\
Faktor perlengkapan & Penerapan ATS & $83.458)$ & \\
(dokumentasi triase) & & $8(1.170-54.72)$ & 0,036 \\
Faktor ketenagaan & Penerapan ATS & & \\
(pendidikan) & Penerapan ATS & $0.059(0.006-$ & \\
Faktor ketenagaan & & $0.628)$ & \\
(pelatihan) & & & 0,013 \\
& & $8(1.170-54.72)$ & \\
\hline
\end{tabular}


Selanjutnya untuk mengetahui faktor yang paling dominan mempengaruhi penerapan digunakan uji regresi logistik. Adapun syarat bagi variabel independen untuk dapat disertakan dalam analisis ini adalah $p$-Value pada analisis bivariat $<0,25$, dengan demikian semua variabel independen dalam penelitian ini dapat disertakan dalam analisis regresi logistik. Analisis regresi logistik pada penelitian ini melalui empat tahapan pemodelan dengan hasil sebagai berikut:

Tabel 2. Hasil Analisis Regresi Logistik

\begin{tabular}{lccc}
\hline \multicolumn{1}{c}{ Variabel } & $\begin{array}{c}\text { Koefisien } \\
(\mathrm{B})\end{array}$ & $\begin{array}{c}p \\
\text { Value }\end{array}$ & $\begin{array}{c}\text { OR } \\
\text { (Cl 95\%) }\end{array}$ \\
\hline $\begin{array}{l}\text { Perlengkapan } \\
\text { (dokumentasi } \\
\text { triase) }\end{array}$ & 1.327 & .238 & 3.771 \\
$\begin{array}{l}\text { Ketenagaan } \\
\text { (pendidikan) }\end{array}$ & -2.313 & .071 & .099 \\
Konstanta & .128 & .902 & 1.136 \\
\hline $\begin{array}{l}\text { Ketenagaan } \\
\text { (pendidikan) }\end{array}$ & 2.833 & .019. & 5.9 \\
\begin{tabular}{l} 
Konstanta \\
\hline
\end{tabular} & 1.224 & 016 & 3.400 \\
\hline
\end{tabular}

Sumber: Data Primer (2017)

\section{PEMBAHASAN}

Pengaruh faktor kinerja (kepemimpinan) terhadap penerapan ATS

Hasil analisis bivariat menunjukkan faktor kinerja (kepemimpinan) dengan penerapan ATS dijelaskan bahwa dari 9 responden yang mempunyai penilaian kurang baik 6 responden menerapkan ATS tidak akurat sedangkan dari 19 responden yang mempunyai penilaian baik 15 responden menerapkan ATS akurat. Hasil uji fisher diperoleh nilai $p=0.028<\alpha=0,05$ maka hipotesis penelitian diterima yaitu ada pengaruh yang bermakna antara faktor kinerja (kepemimpinan) terhadap penerapan ATS. Gibson dalam Suhartati (2015) menyatakan bahwa gaya kepemimpinan dikembangkan oleh seorang pemimpin dipengaruhi oleh tiga faktor (kekuatan) utama. Ketiganya akan menentukan sejauh mana ia akan melakukan pengawasan terhadap kelompok yang dipimpin. Faktor kekuatan yang pertama bersumber dari dirinya sendiri sebagai pemimpin. Faktor kedua bersumber pada kelompok yang dipimpin, dan faktor ketiga tergantung pada situasi.

Kepemimpinan adalah proses untuk melakukan pengembangan secara langsung dengan melakukan koordinasi pada anggota kelompok serta memiliki karakteristik untuk dapat meningkatkan kesuksesan dan pengembangan dalam mencapai tujuan organisasi. Kepemimpinan berarti melibatkan orang lain, yaitu bawahan atau karyawan yang akan dipimpin. 
Kepemimpinan juga melibatkan pembagian atau delegasi wewenang. Pemilihan gaya kepemimpinan yang sesuai harus dilakukan oleh seorang kepala ruang.

Pertimbangan dalam memilih gaya kepemimpinan diantaranya adalah usia dari bawahan, hal ini disesuaikan dengan perkembangan manusia dimana pada usia dewasa muda yaitu 20-40 tahun lebih semangat dalam melaksanakan pekerjaannya yang berkaitan dengan cita-cita dan harapan yang belum tercapai, sehingga untuk mencapai cita-citanya perawat usia muda akan mengikuti pimpinan yang dianggap berpengaruh dan dapat memberikan contoh untuk mencapai kesuksesan. Pada usia ini seseorang mempunyai aktualisasi diri yang tinggi, seorang pemimpin harus mampu mengenali orang lain dan melihat kelebihannya. Usia > 40 tahun, seseorang berada dalam puncak karier, sukses, berprestasi, mengalami kematangan psikologis, sehingga seorang pemimpin harus dapat memilih gaya kepemimpinan mana yang tepat untuk meningkatkan kinerja bawahannya.

Sitohang et al 2017 menyatakan bahwa faktor kepemimpinan merupakan bagian yang sangat penting yang dapat mempengaruhi pelayanan keperawatan serta dapat memberikan kualitas praktik keperawatan yang baik kepada klien.

\section{Pengaruh faktor klien (waktu tunggu) terhadap penerapan ATS}

Hasil analisis bivariat menunjukkan pengaruh faktor klien (waktu tunggu) terdapat 6 dari 8 klien yang waktu tunggunya tidak sesuai standar sedangkan 16 dari 20 klien waktu tunggunya sesuai standar. Hasil uji fisher diperoleh nilai $\mathrm{p}=0.011<\alpha=0,05$ maka hipotesis penelitian diterima yaitu ada pengaruh yang bermakna antara faktor klien (waktu tunggu) terhadap penerapan ATS. Lama waktu tunggu pada penelitian ini merupakan ketepatan waktu dalam memberikan intervensi kepada klien sesuai dengan status kegawatan klien.

Pelayanan yang cepat dan tepat sangat dibutuhkan di dalam pelayanan IGD, pelayanan di IGD dapat terhambat jika kondisi di dalam IGD penuh dengan klien. Kondisi klien yang memenuhi IGD disebabkan oleh tidak sesuainya jumlah klien yang berkunjung ke IGD dengan tenaga dan tempat tidur yang ada di IGD. Standar Prosedur Operasional RSUD Ngudi Waluyo Wlingi, klien dikatakan menunggu apabila klien tersebut berada di IGD selama lebih dari standar waktu tunggu empat jam terhitung mulai triase.

Faktor yang diduga menjadi risiko penyebab waktu tunggu panjang antara lain ketersediaan tempat atau bangsal, tidak sesuainya bangsal yang tersedia dengan permintaan klien, adanya pengelompokan penyakit yang membutuhkan bangsal khusus, menunggu sterilisasi ruang bangsal, kesibukan perawat di bangsal, keterbatasan tenaga pengantar IGD dan keluarga klien. Klien rujukan juga salah satu yang menjadi penyebab kondisi di IGD menjadi semakin penuh. RSUD Ngudi Waluyo Wlingi sebagai rumah sakit rujukan tingkat ketiga, merupakan rumah sakit yang menjadi tujuan utama klien rujukan.

Chen et al. (2010) dan Dadashzadeh et al (2013) mengemukakan bahwa waktu tunggu 
klien adalah rentang antara keputusan rawat inap sampai klien berpindah ke bangsal. Penelitian ini juga menyatakan bahwa ketidaksesuaian kebutuhan dan penyedia pelayanan kesehatan dan kondisi IGD yang penuh atau kunjungan klien yang tinggi merupakan faktor waktu tunggu panjang. Thompson (2006) dalam penelitiannya pada 1631 responden menyebutkan bahwa waktu tunggu, penyampaian informasi oleh staf IGD dan perilaku staf IGD yang ekspresif sangat berpengaruh terhadap tingkat kepuasan klien yaitu positif ( $p$ <.001). Hal ini sesuai dengan hasil penelitian terhadap faktor klien yaitu waktu tunggu (< 4-6 jam) klien di IGD. Hal ini sejalan dengan hasil obervasi setiap shift menunjukkan bahwa waktu tunggu klien di IGD RSUD Ngudi Waluyo Wlingi yang tidak sesuai dengan standar SOP IGD yaitu 4-6 jam sebesar $28.6 \%$ dari total waktu tunggu klien yang diobservasi dikarenakan beberapa faktor yaitu faktor keluarga, administrasi yang tidak lengkap dan ruang rawat inap yang penuh.

\section{Pengaruh faktor perlengkapan (dokumentasi triase) terhadap penerapan ATS}

Hasil analisis bivariate menunjukkan faktor perlengkapan (dokumentasi triase) dijelaskan bahwa 5 dari 7 responden mengisi kurang lengkap dokumen triase menerapkan ATS tidak akurat sedangkan 16 dari 21 responden yang mengisi lengkap dokumen triase menerapkan ATS akurat. Hasil uji fisher diperoleh nilai $p=0.036<\alpha=0,05$ maka hipotesis penelitian diterima yaitu ada pengaruh yang bermakna antara faktor perlengkapan triase (dokumentasi triase) terhadap penerapan ATS.
Penelitian kualitatif Jansen (2011) menyatakan bahwa salah satu faktor yang mempengaruhi dalam pelaksanaan triage adalah sumber daya. Sumber daya (sarana dan prasarana) yang tersedia lengkap dan memadai dapat menunjang penerapan ATS di IGD sehingga pelayanan keperawatan dapat berjalan sesuai dengan prosedur. Sabriyanti, Nur Isnah, Islam dan Gaus (2009) menyatakan bahwa faktor yang mempengaruhi waktu tanggap adalah ketersediaan stretcher dan petugas triage serta kelengkapan dokumentasi triase.

Hasil penelitian Geraci dalam Gerdtz (2009) didapatkan data bahwa faktor-faktor yang mempengaruhi penerapan triase adalah fasilitas fisik lengkap yang disediakan di triase seperti kelengkapan dokumentasi triase. Australian System Process Review (2011) menyatakan bahwa faktor perlengkapan (dokumentasi triase) mempengaruhi penerapan triage oleh perawat.

Hasil observasi pada menunjukkan sebesar $25 \%$ dokumentasi triase tidak diisi lengkap yang sebagian besar pada shift malam yaitu terdapat 10 dokumentasi tidak terisi lengkap padahal hal tersebut mempengaruhi kelancaran prosedur perawatan klien di IGD. Dokumentasi triase yang lengkap sangat berpengaruh terhadap kinerja perawat dalam melakukan intervensi keperawatan kepada klien karena kelengkapan dokumentasi triase merupakan tanggung jawab dan tanggung gugat perawat dalam melakukan tugasnya. Dokumentasi triase yang lengkap juga akan membantu tidak hanya perawat tetapi profesi yang lain yang tidak hanya 
digunakan saat klien di IGD tetapi juga dalam perawatan klien setelah keluar dari IGD.

\section{Pengaruh faktor ketenagaan terhadap penerapan triase}

Hasil analisis bivariat pengaruh faktor ketenagaan (pendidikan) didapatkan bahwa 5 dari 22 responden yang berpendidikan D3 menerapkan ATS tidak akurat sedangkan 1 dari 6 responden yang berpendidikan diatas D3 menerapkan ATS akurat. Hasil uji fisher diperoleh nilai $p=0.013<\alpha=0,05$ maka hipotesis penelitian diterima yaitu ada pengaruh yang bermakna antara faktor ketenagaan (pendidikan) terhadap penerapan ATS.

Hasil analisis pengaruh faktor ketenagaan (pelatihan) terdapat 5 dari 7 responden belum tersertifikasi pelatihan kegawatdaruratan triase menerapkan ATS tidak akurat sedangkan 16 dari 21 responden yang sudah tersertifikasi pelatihan kegawatdaruratan klinis triase menerapkan ATS akurat. Hasil uji fisher diperoleh nilai $p=$ $0.036<\alpha=0,05$ maka hipotesis penelitian diterima yaitu ada pengaruh yang bermakna antara faktor ketenagaan (pelatihan) terhadap penerapan ATS.

Tingkat pendidikan terbanyak perawat IGD RSUD Ngudi Waluyo adalah D3 sebesar $22(78,6)$, diatas D3 (S1 $5(20)$ dan S2 $1(1,4)$ )dengan lama masa kerja 0-2 tahun sebesar $19(67,8), 3-5$ tahun $6(21,5)$ dan $>5$ tahun 3 $(10,7)$ dan sebagian besar 21 (75) sudah mengikuti pelatihan kegawatdaruratan klinis yang tersertifikasi triase oleh ENA 2005, key performance indicator Depkes 2009 (BTLS/ATLS/ACLS/GELS/PPGD).
Penelitian Quasi-Interventional Study Rahmati, Azmoon, Meibodi, Zare 2013 pada 50 staf RS Hospital of Fasa University of Medical Sciences menyebutkan hasil yang signifikan sebelum dan sesudah mendapatkan pelatihan triase selama 6 bulan dengan kinerja keperawatan di IGD ( $r=0.258$, $\mathrm{p}=0.032$ ). Penelitian ini juga sejalan dengan penelitian Jansen (2012) menunjukkan bahwa faktor yang mempengaruhi pelaksanaan triage yaitu salah satunya adalah tingkat pendidikan, pelatihan dan pengalaman.

Hasil perhitungan dan analisis data yang telah dilakukan pada penelitian Fatimah 2007, variabel tingkat pendidikan, motivasi, usia dan pengalaman kerja secara bersama sama memberikan pengaruh positif dan signifikan terhadap variabel produktivitas kerja perawat. Hal tersebut ditunjukkan dengan hasil uji $F(\alpha=5 \%)$ sebesar $27,860>$ $F$ tabel sebesar 8,25. Hipotesis pertama dari penelitian ini yaitu bahwa terdapat pengaruh yang signifikan antara variabeltingkat pendidikan, motivasi, usia dan pengalaman kerja terhadap variabel produktivitas kerja terbukti kebenarannya dengan nilai t hitung sebesar 3,894 $\geq 1,980$ (t hitung $>\mathrm{t}$ tabel) maka hal tersebut menunjukkan bahwa variabel tingkat pendidikan memiliki pengaruh paling dominan terhadap produktivitas kerja perawat dalam menerapkan triase di IGD.

Variabel pengalaman kerja mengikutinya dengan nilai thitung sebesar 3,853, motivasi 2,983, usia 2,022 dengan demikian hipotesis kedua yaitu bahwa variabel tingkat pendidikan memiliki pengaruh yang paling dominan terhadap variabel produktivitas kerja terbukti kebenarannya. Analisis 
koefisien determinasi variabel tingkat pendidikan, motivasi, usia dan pengalaman kerja memberikan pengaruh sebesar 56,2\% terhadap variabel produktivitas kerja perawat. Kesimpulan penelitian ini adalah tingkat pendidikan, pengalaman kerja, dan usia mempunyai pengaruh yang cukup besar pada kinerja keperawatan dalam hal ini adalah penerapan ATS pada klien yang datang ke IGD.

Penelitian Ahmad, Murtaja (2014) menyatakan bahwa besarnya pengaruh pelatihan terhadap kinerja perawat sebesar 19.3\%. Hasil perhitungan secara parsial diperoleh $\mathrm{t}$ hitung sebesar 3.823 dengan tingkat probabilitas 0.000 lebih kecil dari 0.05. Hal tersebut berarti terdapat pengaruh pemberian pelatihan terhadap kinerja perawat di RSI NU Demak.

Pendidikan merupakan faktor yang mempengaruhi kinerja seseorang namun dalam penelitian ini banyak faktor lain juga mempengaruhi kinerja seseorang, diantaranya disebabkan karena jumlah sampel yang tidak merata, selain itu meskipun sebagian besar responden mempunyai tingkat pendidikan pemula, namun mempunyai pengalaman kerja yang sudah lama, dan sering mendapatkan pelatihan. Pelatihan klinis keperawatan kegawatdaruratan yang berkesinambungan dan berkelanjutan dapat meningkatkan pengetahuan dan keterampilan klinik yang juga menentukan kinerja seseorang dalam menerapkan ATS di IGD.

\section{Faktor dominan yang memepengaruhi penerapan ATS}

Hasil uji menunjukkan bahwa yang memenuhi syarat tersebut adalah faktor ketenagaan (pendidikan) yaitu $\mathrm{p}=0.019$ dengan nilai OR 17.0 sehingga variabel ketenagaan (pendidikan) mempunyai kekuatan hubungan paling dominan dibandingkan dengan variabel yang lain sedangkan untuk melihat kualitas analisis multivariat dilihat melalui kemampuan kalibrasi dan diskriminasi dengan metode Hosmer and Lameshow didapatkan nilai $\mathrm{p}=$ 0.572 ( $p=0.05$ ) sehingga persamaan yang didapatkan dari hasil analisis multivariat layak digunakan untuk menentukan faktor yang berpengaruh terhadap penerapan Australasian Triage Scale.

Penilaian diskriminasi dapat menggunakan nilai Area Under Curve (AUC) yaitu dikatakan baik jika nilai AUC lebih dari $50 \%$ atau semakin mendekati angka 1. Hasil nilai AUC diperoleh nilai sebesar 0.827 atau $82.7 \%$ kategori kuat yang berarti persamaan hasil analisis multivariat layak digunakan untuk menentukan faktor yang berpengaruh terhadap penerapan Australasian Triage Scale.

Hasil perhitungan dan analisis data yang telah dilakukan pada penelitian Fatimah (2007), variabel tingkat pendidikan, motivasi, usia dan pengalaman kerja secara bersama sama memberikan pengaruh positif dan signifikan terhadap variabel produktivitas kerja. Hal tersebut ditunjukkan dengan hasil uji $F(\alpha=5 \%)$ sebesar $27,860>F$ tabel sebesar 8,25. Dengan demikian hipotesis pertama dari penelitian ini yaitu bahwa terdapat pengaruh yang signifikan antara variable tingkat pendidikan, motivasi, usia dan pengalaman kerja terhadap variabel produktivitas kerja terbukti kebenarannya bahwa variabel tingkat pendidikan memiliki pengaruh paling dominan terhadap produktivitas kerja. 
Variabel pengalaman kerja mengikutinya dengan nilai thitung sebesar 3,853 , motivasi 2,983, usia 2,022 dengan demikian hipotesis kedua yaitu bahwa variabel tingkat pendidikan memiliki pengaruh yang paling dominan terhadap variabel produktivitas kerja terbukti kebenarannya.

Analisis koefisien determinasi variabel tingkat pendidikan, motivasi, usia dan pengalaman kerja memberikan pengaruh sebesar 56,2\% terhadap variabel produktivitas kerja perawat. Kesimpulan penelitian ini adalah tingkat pendidikan, pengalaman kerja, dan usia mempunyai pengaruh yang cukup besar pada kinerja keperawatan dalam hal ini adalah penerapan ATS pada klien yang datang ke IGD.

Faizin 2008 melakukan penelitian kepada 107 perawat RSU Pandan Arang Boyolali yang hasilnya menyatakan bahwa ada keterkaitan atau hubungan antara tingkat pendidikan perawat dengan prestasi kerja keperawatan begitu juga dengan lama kerja perawat berhubungan dengan kinerja keperawatan. Hasil penelitian Santosa 2015 menunjukkan bahwa hubungan yang sangat kuat antara pengetahuan dan tindakan perawat $p=0,002 ; r=0,802$.

Karakteristik perawat IGD RSUD Ngudi Waluyo Wlingi Kabupaten Blitar berpendidikan D3 sebesar $22(78,6)$ dan diatas D3 sebesar 6 (S1 5 (20) dan S2 $1(1,4)$ ) dengan pengalaman kerja terbanyak adalah 0-2 tahun sebesar $19(67,8)$. Perawat yang berstatus kepegawaian PNS sebesar $16(57,14)$ sedangkan yang mempunyai pelatihan kegawatdaruratan tersertifikasi triase (BTLS/ ATLS/ACLS/GELS/PPGD) sebesar 21 (75).
Hal ini berarti bahwa perawat IGD RSUD Ngudi Waluyo Wlingi berkarakteristik ketenagaan dengan tingkat pendidikan kategori menengah dan termasuk usia dewasa awal produktif yang mempunyai pelatihan klinis kegawatdaruratan tersertifikasi triase dan sudah berpengalaman dalam bekerja di IGD sehingga bisa menerapkan Australasian Triage Scale secara akurat.

Hasil penelitian menyatakan bahwa sebagian besar perawat akurat menerapkan ATS yaitu 18 (64.3) dengan OR sebesar 46.50.82.0. Hasil observasi menunjukkan bahwa perawat sebagian besar sudah menerapkan ATS secara akurat baik dari klasifikasi level kegawatan ataupun waktu tanggap dalam penanganan pada klien yang datang ke IGD RSUD Ngudi Waluyo Wlingi. Hasil observasi juga menunjukkan bahwa 10 (35.7) perawat IGD tidak akurat dalam menerapkan ATS yang seharusnya diharapkan bahwa tingkat keakuratan di IGD adalah $100 \%$ berati $0 \%$ kesalahan sehingga klien bisa diberikan intervensi sesuai dengan kegawatannya karena ketidaktepatan intervensi mengakibatkan nyawa klien terancam.

Hal ini sejalan dengan Forero (2012) yang menyatakan bahwa triase dilakukan untuk memastikan bahwa klien dirawat berdasarkan level urgensi klinis, memastikan pengobatan yang tepat dan tepat waktu, menempatkan klien dengan penilaian yang paling tepat, menentukan daerah perawatan yang tepat serta mengumpulkan informasi yang dapat berguna bagi pengembangan triase di IGD.

Klien dengan level triase merah dengan urgensi klinis yang paling tinggi menunjukkan 
lama perawatan yang lebih lama dari level triase dibawahnya. Hal yang sama dijelaskan oleh Gilboy 2010 yang menyebutkan bahwa level triase merah menunjukkan kondisi gawat dan darurat yang mengandung makna bahwa klien dalam kondisi yang mengancam jiwa dan harus segera ditangani. Kondisi mengancam jiwa tersebut membutuhkan penanganan yang lebih komplek. klien dengan level triase merah secara nyata menampilkan gangguan pada airway, breathing atau circulation sehinga dibutuhkan proses resusitasi yang membutuhkan tindakan kompleks seperti airway management, serta monitoring yang ketat dan lebih lama sebelum diputuskan

\section{DAFTAR PUSTAKA}

Aloyce, R., Leshabari, S., Brysiewicz (2014). Assessment of knowledge and skills of triage among nurses working in the emergency centers in dar es salam Tanzania. Journal African Medicine, 6(2): 114-121

Baker, T. (2009). Critical care in low income countries. Trop med int health.p 409-415

Chen, S. S., Chen, J. C., Ng, C. J., Chen, P. L., Lee, P. H., \& Chang, W. Y. (2010). Factors that influence the accuracy of triage nurses' judgement in emergency departments. Emergency Medicine Journal, 27(6), 451-455.

Dadashzadeh, A., Abdolahzadeh, F., Rahmani, A., \& Ghojazadeh, M. (2013). Factors affecting triage decision-making from the viewpoints of emergency department staff in Tabriz hospitals. Iran J Crit Care Nurs2013, 6(4), 269-276. untuk dilakukan proses pemindahan ke unit lain.

\section{SIMPULAN}

Terdapat pengaruh yang bermakna faktor kepemimpinan, faktor klien (waktu tunggu), faktor dokumentasi triase, faktor pendidikan dan pelatihan dimana pendidikan merupakan faktor prediktor yang paling mempengaruhi penerapan ATS.

Perlu disusun kebijakan pengembangan dan peningkatan sumber daya keperawatan melalui pengembangan program pelatihan kegawatdaruratan klinis berkelanjutan dan pendidikan keperawatan berjenjang.

Emergency Nurses Association. (2014). Standards of emergency nursing practice $5^{\text {th }}$ ed., USA: lippincot Comp., pp 56-60

FitzGerald, G., Jelinek, G. A., Scott, D., \& Gerdtz, M. F. (2010). Republished paper: Emergency department triage revisited. Postgraduate medical journal, 86(1018), 502-508.

Forero, R. (2012). Australasian College for Emergency Medicine (ACEM) literature review on the Australasian triage scale (ATS) (Doctoral dissertation, Institute of Health Innovation, University of New South Wales)

Gerdtz et al. 2009. Factors influencing consistency of triage using the Australasian Triage Scale: Implications for guideline development (original research). EMA

Gilboy, N. (2010). Sheehy's EmergencyNursing Principles and Practice. SixthEdition. 
Edited by Howard, P.K., \&Steinmann, R.A. St.Louis, Missouri : Mosby Elsevier.

Gilboy, N., Tanabe, T., Travers, D., \& Rosenau, A. M. (2011). Emergency Severity Index (ESI): A triage tool for emergency department. Rockville, MD: Agency for Healthcare Research and Quality. Retrieved

Janssen, M. A., van Achterberg, T., Adriaansen, M. J., Kampshoff, C. S., Schalk, D. M., \& Mintjes?de Groot, J. (2012). Factors influencing the implementation of the guideline triage in emergency departments: a qualitative study. Journal of clinical nursing, 21(3?4), 437-447.

Republik Indonesia. (2008). Nomor 129/ Menkes/SK/II/2008. Tentang Standar Pelayanan Minimal Rumah Sakit. Kemenkes R.I. Jakarta.

Lee, J. Y., Oh, S. H., Peck, E. H., Lee, J. M., Park, K. N., Kim, S. H., \& Youn, C. S. (2011). The validity of the Canadian Triage and Acuity Scale in predicting resource utilization and the need for immediate life-saving interventions in elderly emergency department patients. Scand J Trauma Resusc Emerg Med, 19, 68.

Lusiana 2011. Pengaruh Tingkat Pengetahuan dan sikap perawat dengan pelaksanaan Triage di IGD RS Puri Indah Jakarta

Safari, S. R. (2012). Perceptions and challenges of using emergency triage assessment treatment guideline in emergency department at Muhimbili national hospital, Tanzania (Doctoral dissertation, Muhimbili University of Health and Allied Sciences). downloaded on February, 6, 2017

Sitohang, H., Santosa, H., \& Salbiah, S. (2017). Hubungan Fungsi Supervisi Kepala Ruangan dengan Produktivitas Kerja Perawat Pelaksana di Rumah Sakit Umum Daerah dr. Pirngadi Medan. Idea Nursing Journal, 7(1), 13-19.

Suhartati. (2015) .Media Pengembangan SDM Kesehatan, 1(1),76-81 